saturating distilled water samples with hydrogen, helium, oxygen, nitrogen, and air, respectively.

As a result of fifteen sets of observations, the water con. taining the dissolved carbon dioxide consistently evaporated more rapidly than the control water sample. The increase in evaporation varied between 15 and 50 per cent. This was undoubtedly due to the fact that the amount of carbon dioxide dissolved in the water was not kept constant. The gas was bubbled through the water at various temperatures; since solubility decreases with increasing temperature one could expect a smaller effect at higher temperatures. This, in fact, was observed: when the temperatures were higher and the evaporation rates were also higher, the increase in evaporation rate due to carbon dioxide in solution was less.

On the average the measurements revealed a 30 per cent increase in evaporation of the water containing the carbon dioxide over the control samples. No significant difference in evaporation rates was detected when other gases were substituted for carbon dioxide. The results of these experiments suggest the desirability of continuing the investigation with more elaborate experimental design using various gaseous environments.

All possible experimental errors were scrutinized. First, it was suggested that the carbon dioxide escaping from the water surface would sink in the lighter environment of air and set up convection currents which would enhance evaporation of the water. To prevent this, carbon dioxide was introduced into the chamber so that buoyancy effects would be avoided. This did not alter the results reported here. Second, since carbon dioxide strongly absorbs infra-red radiation, we examined the possibility that the sample containing carbon dioxide would absorb more heat from the projector beam than the plain water sample and thereby evaporate faster. To test this, the projector lamp was turned on only for the very short periods of time required for recording the height of the meniscus.

The more rapid evaporation of the sample containing carbon dioxide continued. Third, to ensure that the control and test chambers were identical and that they were subject to essentially the same ambient conditions, many runs were made in which both chambers contained plain water samples. In each case, the evaporation rates were then the same.

Using the most pessimistic estimates of these and various other possible errors, I found that their influence on the evaporation rate is negligible when compared with the observed effect reported here.

Department of Meteorology,

College of Mineral Industries,

Pennsylvania State University, University Park, Pa.

\section{Alignment of Cirrus Clouds along the Magnetic Meridian}

CirRus clouds appear very often in a regular array of parallel bands. Alexander von Humboldt ${ }^{1}$ discovered in the course of his meteorological observations in South A.merica and Siberia that these arrays follow frequently the line of the geomagnetic meridian of the locality; he invented the term "bandes polaires" for this phenomenon. Even very casual observations confirm the truth of his statement. He suspected some connexion between the appearance of these 'polar bands' and that of the aurora borealis. In the light of present-day knowledge of the composition of cirrus clouds, it is possible to put forward an explanation of this alignment. Since the constituent ice particles are known to form around dust particles of partly meteoric origin, they will align along the lines of force of the geomagnetic field in those cases in which the dust core consists of a magnetic material. It follows incidentally that the concentration of magnetic meteoric dust in the upper atmosphere should increase from the equator towards the poles, a hypothesis which is confirmed by Sobermann's ${ }^{2}$ recent work on the composition of noctilucent clouds above northern Sweden.

Humbold $t^{3}$ observed, furthermore, that the alignment of cirrus clouds is more often seen and is of longer duration near the equator than in northern latitudes where their direction gradually changes from that of the magnetic meridian to an east-west line. This movement of the cirrus bands may be due to the action of the jet streams which occur at approximately the same height as cirrus clouds. It seems therefore that observations of the occurrence and movement of aligned cirrus bands may be of use in the investigation of the force and direction of jet streams.

Imperial College of Science and Technology,

L. KELLNER London, S.W.7.

1 Humboldt, A. von, Kosmos, 1, 441, note 44 (1845).

2 Humbold, A. von, Kosmos, 1, 51 (June 1963).

${ }^{3}$ Humboldt, A, von, Kosmos, 4, 145 (1858).

\section{GEOLOGY}

\section{$F_{2}$ Quartz Veining in the Manx Slate Series}

THE geological foundation of the Isle of Man is an aged, complex sequence of slates, flags and greywacke, termed the Manx Slate Series. This thick geosynclinal pile, apparently of Cambrian age, outcrops over the greater part of the Island.

Previousresearch by $\mathrm{me}^{1}$ has demonstrated the polyphase structural history of the Manx Slate Series during the Caledonian orogeny. Three distinct episodes of tectonic movement $\left(F_{1}, F_{2}, F_{3}\right)$ each formed large-scale folds, a suite of congruous minor flexures and an axial-plane cleavage $\left(S_{1}, S_{2}, S_{3}\right)$.

The $F_{1}$ fold-system is characterized by steep, acute flexures and the accompanying $S_{1}$ is a flow cleavage in pelite. The subsequent $F_{2}$ and $F_{3}$ folds possess a more open, right-angled style, but are easily distinguished by their difference in orientation. The axial planes of the $F_{2}$ flexures are flat-lying or gently inclined while those of the $F_{3}$ generation dip steeply and consistently to the northeastern quadrant. The related $S_{2}$ and $S_{3}$ are strain-slip cleavages. A syn-tectonic $F_{1}$ metamorphism produced the mild, chlorite-zone alteration which characterizes these strata ${ }^{2}$.

Throughout the Isle of Man the plicated Manx Slate Series is traversed by conspicuous quartz-veining. Individual veins usually vary from a fraction of an inch up to several inches thick though instances measurable in feet are not uncommon. This veining only rarely accompanies the more severe $F_{1}$ deformation. The widespread injection of most of the white vein-quartz occurred during the second $\left(F_{2}\right)$ movement-phase and is characteristically associated in the field with mesoscopic $F_{2}$ structures. The veining becomes particularly intense and abundant at loci where minor $F_{2}$ folding is severe, emphasizing its syn-kinematic nature. The most favourable host rocks are the uniform pelite of the slate formations and the thinly striped strata of the various banded groups. The veining is less abundant in flaggy units. In the Barrule Slates, the contrast between the dark pelite and the white quartz is particularly striking.

The $\mathrm{F}_{2}$ quartz-veining adopts three main modes of occurrence controlled to a large extent by the time of emplacement during the $F_{2}$ movement. These are: (1) concordant veining; (2) discordant veining; (3) irregular veining.

Concordant veining was emplaced along either bedding or $S_{1}$, whichever was the dominant $S$-plane, during $F_{2}$ flexural-slip. After injection, such veining was later implicated in the crumpling and effectively outlines the $\mathbf{F}_{\mathbf{2}}$ contortions. In places the veining is cut by 